\title{
Feasibility and Implementation Approach on Introduction of Recessive Education in Children's Sports Activities
}

\author{
Fei Wang ${ }^{a}$, Ying Zhang ${ }^{b}$ \\ College of Education and Sports, Bohai University, Jinzhou, 121013, China \\ a839680698@qq.com, b47086132@qq.com
}

Keywords: children; sports activities; recessive education; feasibility; implementation approach

\begin{abstract}
Along with social attentions to the children's physical education is more and more high, one-sided teaching and one-way infusion in the past, the children who are regarded simply as passive recipients, the education concept of ignoring children's subjective feelings, which has been unable to meet the development demand of today's children's sports education. How to improve the effectiveness of children's physical education, which has become an important subject of sports researchers. As one of the contents of education, the role recessive education plays in preschool physical education should not be ignored. Based on the perspective of recessive education, this paper expounds the connotation of recessive education, analyzes the feasibility and function of recessive education in children's sports activities, and puts forward the implement way of recessive education in children's sports activities. The purpose is to carry on the charm of recessive education in children's sports activities.
\end{abstract}

\section{Introduction}

With the high-speed development of Chinese sports, people pay more and more attention to children's sports. More parents invest more energy and money for their children thriving more healthily. There are also more and more kindergartens, through the curriculum reform and continuous improvements of hardware facilities, which meets people's needs for preschool physical education. However, in the tide of children's sports development, people pay too much more attention to the cultivation of children's sports knowledge and skills, more on the reform of the dominant education of the preschool sports, who tend to ignore the recessive education in children's sports. Dewey once said: "perhaps the biggest failure of the current teaching is only in the specific time to teach children specific things". Compared with the students in the field of ordinary education, children have their unique physiological and psychological characteristics, distinct characteristics which are owned to children on the cognitive ability of sports environment, the obedience attitude towards the rules of sports games, as well as the imitation and dependence of the behavior of teachers. Therefore, the role of integrating the recessive education into preschool physical education is more obvious.

\section{Connotation of Recessive Education}

In 1968, American scholar Jackson W Philip first proposed the hidden curriculum, English name is written as hidden curricu-lum, or informal curriculum and covert curriculum and so on, the Chinese translation form is also varied, there are hidden curriculum and invisible curriculum, potential curriculum and non dominant curriculum, informal curriculum and so on. Mr Zhang Chuting believes that hidden curriculum is better than invisible curriculum and potential curriculum to say, the direct implication of hidden is that recessive, concealment, rather than the potential meaning, latent(curriculum)has potential or latent meaning [1]. Throughout the domestic research literature, all tends to be the word "hidden curriculum". And then, the recessive education as an upper concept of hidden curriculum gradually appears in educational circles.

So far, academic circles have different definition angles for recessive education, which is more mature definition is that integrate various angles to define, especially the attention from psychological acceptance mechanism of education to excavate the deep connotation of recessive 
education, such as that "recessive education is relative to the dominant education, it refers that the education makes influences on the thought, behavior, emotional and psychological and others of object, such as blending teaching in school, teaching through lively activities, education with tube are all important forms of recessive education" [2].

Throughout related research literatures, the author thinks that the key of defining recessive education is the scholars' view on the "hidden" word, as a supplement to the dominant education, recessive education is a kind of indirect, implicit and pervasive education method, in a kind of "informal" education form, which makes people unconsciously influenced. In fact, throughout the history of China's five thousand years, before the concept of recessive education is formally proposed, our country education ideological circle already exist related education concepts. Among them, the most typical way is nothing better than the example that traditional education implemented "mother Meng moves three times," in the story mother Meng moves three times with pains in order to give the children a better education environment, except that there are some common idioms, such as "monasteries", "osmosis," and "set an example", "who lies near the ink black", "sex is similar, their habits that separate them" and so on; Countless, these Chinese cultures handed down from generation to generation undoubtedly show the long history of recessive education in our country.

\section{Function of Sports' Recessive Education}

Since ancient times, "sports" with respect to other educations, the most important significance lies in strengthening physical health, so people tend to easily ignore the effects of sports on other aspects of the participants, however, with the rapid growth of economy, the continuous advancement of era, our country gradually develops into a sports power country, people's demands for sports are no longer confined to strengthen physical health, so the understanding of sports can also be no longer limited to the role of the surface, based on this, investigate the role of recessive education in sports activities can make preschool education workers mine sports value at a better and deeper level, at the same time, also conducive to implement comprehensive quality education at present in our country [3].

Sports teaching is different from general literacy class teaching. First of all, teaching places are set in the outdoor, relative to other academic teaching, which have a great deal of openness, hold the advantages of physical space environment, and the material space environment is the potential teacher of children's education, which is an important education resource. The design of the teaching place, placement of equipment, venue settings all have certain education significance. Not only through their own perfect degree restricting and influencing the content and level of teaching activities, and making different effects on the teachers and students with some own external characteristics, it helps to improve the students' cognitive structure, stimulate students' learning motivation and desire for knowledge, promote the improvement of students' comprehensive quality and the development of intelligence, so that students can master a lot of knowledge which cannot be learned in books, which has strong practicality [4]. At the same time, in the process of sports teaching, students learn not only sports technology, but also the improvement of quality, psychological quality, body quality and so on, when students make sports activities, gradually improve their various aspects abilities [5]. Finally, sports teaching cannot be separated from competitions, competitions have corresponding regulations and rules, so children in the process of continuous participation in sports activities, except that learning the basic sports knowledge and skills, but also consciously or unconsciously influenced by different kinds of institution and rules, abide by a certain organizational discipline, standardize their own behavior, enhance the consciousness of action and the ability of self-discipline and self-adjustment, develop a good sports habits. Therefore, it is of great significance for the recessive education in sports activities.

\section{Recessive Education in Children's Sports Activities}

Infant stage did not has many so-called sports skills and skill learning, children's nature is lively, 
compared with the single action description, they are more likely to internalize the things teachers do into action, so sports activities with rich and various of contents and forms are more attractive to them, teachers strive to do is to let the children grow continuously in a variety of sports activities such as continuous walking, running, jumping, climbing and so on, and develop good sports exercise habits [6]. However, which did not achieve the desired effect in the actual daily life. For the kindergarten children, what shows more often is a kind of open education of concentrated "high control", there are no real autonomy and freedom for children. The author once interviewed a principal of a kindergarten, in the process of interview she called the children a bird lives in the "cage", their growth environment is closed, change every day is just flying from "small cage" of the family to "big cage" of the kindergarten, the opportunities of contacting with social are limited, and children is the basis of our growth, they are unknown to society, for these cases, children sports education workers should know more that integrate recessive education into children's daily sports activities. Attention should be paid to teaching children some basic sports skills, at the same time, full use of this kind of education that recessive education should be made, making use of children's imitation and plasticity to promote children to become a real regular freemen. Let children experience the sports spirit in sports activities, understand how to behave and how to become a better person, through improving their ability to deal with setbacks in sports activities, so that they have a good psychological quality, all of these become particularly important. As Gorky said: "the game is the way of understanding the world and transforming the world for children". Teachers should make full use of this way.

\section{Feasibility Analysis on Introduction Recessive Education in Children's Sports Activities}

Introduction of recessive education in children's sports activities is the need to improve the effectiveness of children's sports activities. In today's rapid development twenty-first century, in the past that children are simply regarded as passive recipients, one-sided emphasis on simple teaching and one-way infusion, education idea of ignoring children's subjective feelings, which have been unable to meet the development needs of today's children's sports education. In recent years, the implementation effect of children's sports activities is not satisfactory, the main reason is that in the process of children's sports activities, the research and application of recessive education are not enough, at the same time, the attention on development and utilization of recessive education resources in sports activities is not enough. Therefore, making full use of exploration, development and utilization of recessive education resources has an important significance for improving the effectiveness of children's sports activities [7].

Introducting recessive education into children's sports activities is a supplementary need of explicit education. As a supplement to explicit education, recessive education is a kind of indirect, implicit and penetrative education method. Its implementation is not mandatory, it is in the pleasant atmosphere, so that students unconsciously accept education. Its main characteristics are occult, indirectness, permeability, equality and persistence. In the process of children's sports activities, properly using the method of recessive education can make contents and forms of children's sports activities more rich and colorful, the teaching effect is more obvious, more easy for children to accept. In the process of children's sports activities, recessive education is different from the direct education way of explicit education, which is a kind of way of "the wind into night, moistens everything silently" to attract children's attention, arouse children's subjective enthusiasm, cultivate children's sports interest and so on, through recessive education in sports activities strengthen students' ability of social communication and social adaptation, so that realize all-round development of individuals better. At the same time, strengthen recessive education can better cultivate children's social role, so that children can be smoothly integrated into social life. However, these are also the things dominant education cannot give in children's sports activities, to some extent, that is a very good supplement to the dominant education.

Introducting recessive education into children's sports activities is the need to promote children all-round growth. The influence of recessive education to children is all-wave, involving all aspects of cognition, emotion, trust, meaning, behavior [7]. In the process of children's sports activities, the 
implementation of recessive education can promote children's personality to get constantly development and perfection, so as to promote children all-round development. Children's growth and living environment is limited to school and family in the contemporary era, school is the main place children accept education every day, so their growth environment is too closed, the opportunities of contacting with social are limited, this phenomenon becomes a realistic problem faced with current children education. Children is the basis period for growth, their understanding of society is unknown, according to these conditions, when children's sports education workers teach children some basic sports skills, full use of this kind of education form that recessive education should be made, which lets children feel sports spirits in sports activities, understand the truth of being a person. Through improving their abilities to deal with setbacks in sports activities, which makes them have a good psychological quality, enhances the social adaptation ability [8]. In this way, children can form a healthy, optimistic, positive attitude towards life.

\section{Implementation Approach on Introduction Recessive Education in Children's Sports Activities}

First approach, make full use of material space resources. Environment is a potential teacher for children education, important education resources. [9] Kindergarten is the main place for children's daily activities, most of sports activities are carried out in the kindergarten, kindergarten teachers should give full play to the role of home, reasonably and properly making use of kindergarten material space resources to bring children better into the sports game world. For example, design sports style on school corridor, paths, classroom style. Kindergarten can stick on various patterns of big feet with different sizes and shapes in the corridor or on the path of back and forth to the classroom, when pass the road, children can't help jumping with pattern; Similarly also can be in the great hall of kindergarten or classroom hanging on a variety of small ornaments, so that children can do vertical jump game independently; At the same time, the display style of classroom desks and chairs does not need to be in accordance with the regular arrangement of middle and primary school, let children have more space to do sports small games and so on. In addition, clever use of kindergarten sports field equipment. kindergarten teachers before class can take out sports equipment with rich color style, chose by children according to personal preferences, and grouped according to color and shape; equipment placed into various shapes and patterns according to the content of this lesson before class, such as basketball emissions into snake-shape, s-shaped, square and so on, let children move along basketballs, so as to increase the interesting of classes.

Second approach, rectify spiritual culture view. Firstly, school leadership should attach great importance to the concept of recessive education in children's sports, has correct leadership style, establish a good campus and class atmosphere, build thick sports atmosphere. It is so-called that leadership level determines the development level of a unit, therefore, leadership level should increase the degree of attention, participation and investment to children's sports recessive education. Secondly should make full use of the influence role of children teachers, through raising the overall level of teachers, which establishes the harmonious relationship between teachers and students. Because education on both sides is equal in the process of recessive education, there is no unilateral rigid instillation, everyone can express their own views, but also can selectively accept the views of others, making sports activities on the basis of the relationship between teachers and students get along well can arouse children's subjective interest, stimulate their active participation, this real significance that arousing the enthusiasm and participation of education objects is the ideal education effect recessive education can achieve. Meanwhile, when in the play to teachers' teaching main body status, also cannot ignore the family and social influence on children's sports recessive education. For example in the school teachers let children through sports activities know to do things to have a firm will, but in the family, parents are blindly to instill this idea "do not have nothing to do, parents help you", then the effect of school will be certainly affected, the effect of recessive education will also be greatly discounted. Therefore, parents should pay attention to their own words and deeds when have sports with children, improve their own self-cultivation, take a good example for children. 
Third approach, integrate recessive education into the forms of teaching contents of children's sports. In the process of implementing sports recessive education for children, firstly correctly orientate the basic characteristics of children, clear understand the changes of different physical and psychological characteristics between children, adolescents and adults. For example, such as in the teaching of running sports activities, because children's concentration time is not long, especially sports place is located in the outdoor, teachers should adopt recessive education methods at this moment, make some dry running vivid. In addition, simply running can also be transformed into adults games, which exercises children running ability as well as increases the emotional communication between students. Teaching children how to abide by the rules of the game in children's sports activities cannot be done overnight, which follows the idea teach "comply with the rules of sports" step by step in the sports activities, makes full use of the teaching methods of recessive education of situational teaching method, example method, group cooperative teaching method, suggestive teaching, incentive teaching method and so on.

Fourth approach, explore comprehensive education model of the combination of school, family and social. When make recessive education, play the school teaching main body status, also cannot ignore the influence of family and society on children's recessive education. Through children's sports activities implementing recessive education must set up system education idea, take the recessive education in children's sports activities as the common task of whole society. Establish a system education concept, make full mobilize of the strength of three aspects of school, family and society [10]. First of all, play the role of schools' home, through the ways increasing the degree of attention school leaders pay on children's sports recessive education, strengthening children teachers education modes, personal accomplishment cultivation and so on, so that children get all-round influence unconsciously. Secondly, paying more attention to family education, elaborating family sports activities, that is the important role of recessive education in sports activities. Finally, the significance of social support for infant sports recessive education also cannot be ignored, society should build a good sports activities atmosphere, create a positive social environment for children's sports activities.

\section{Conclusion}

This study emphasizes the reasonable use of the recessive education method in children's sports activities, with the children loved way to attract their interests, but also its education goal can not be ignored. If only understand the recessive education method as simple "edutainment", which will restrict the scope of education, narrow the carrier and means of education, inevitably lead to the narrowness and one-sided of the understanding for the recessive education methods [10]. At the same time, also cannot blindly only emphasizing the importance of recessive education in children's sports activities, however, ignoring the most basic dominant education methods, we should learn to correctly grasp the relationship between them in the practice of education, cleverly combine recessive education and dominant education, which makes children lively and cheerful, comprehensive and healthy growth.

\section{Acknowledgement}

This work is supported by general subject of "the Twelfth Five-year Plan" on educational science of Liaoning province: Action research on feel integrative training into the children's sports activities, 2015, Approval (JG15CB167). 


\section{References}

[1] Q. L. Cui, J. H. Zhang, "Review of the research on the hidden curriculum in domestic universities," Journal of Hunan University of Technology, vol. 16, no. 3, pp. 85-88, 2011.

[2] A. X. Xu, Y. S. He, "On recessive education in political education in universities," Truth Seeking, vol. 21, no. 2, pp. 13-4, 2008.

[3] H. Chen, J. S. Zhou, "The feasibility analysis of the operation of the implicit education in the family education," Neijiang science and technology, vol. 16, no. 12, pp. 189-191, 2010.

[4] S. C. Wang, "Recessive education function in developing physical education," Higher education in China, vol. 33, no. 8, pp. 35, 2000.

[5] Z. F. Du, "Application of recessive education in Physical Education," Science and Technology Education, vol. 24, no. 5, pp. 34, 2014.

[6] H. H. Cao, " The charm of recessive education in sports activities," Journal of Taiyuan University School of Education, vol. 32, no. 3, pp. 24-27, 2014.

[7] S. Tang, "Research on implicit education in college ideological education," Master's degree of Liaoning Normal University, 2009.

[8] D. Q. Hao, "Analysis of implicit education in physical education from the perspective of Psychology," Bulletin of Sport Science\& Technology, vol. 19, no. 5, pp. 50-51, 2011.

[9] Z. H. Shi, "Research and enlightenment of the hidden curriculum in kindergarten," Master's degree of Hebei University, 2011.

[10] S. Zhao, "Research on the methods of recessive ideological and political education in universities," Master's degree of Capital University of Economics and Business, 2014. 